\title{
NOUVELLE
}

\section{Interféron de type I et sélectivité de l'infection des cellules du système nerveux central par le virus de la rougeole}

Marion Ferren, Branka Horvat, Denis Gerlier, Cyrille Mathieu

\author{
Centre international de recherche en infectiologie (CIRI), \\ équipe d'immunobiologie des infections virales, Univ Lyon, \\ Inserm U1111, Université Claude Bernard Lyon 1, CNRS \\ UMR5308, ENS de Lyon, 21 avenue Tony-Garnier, 69007, Lyon, \\ France. \\ marion.ferren@inserm.fr \\ cyrille.mathieu@inserm.fr
}

> L'infection par le virus de la rougeole reste une cause majeure de morbidité et de mortalité dans le monde [1]. Malgré la disponibilité d'un vaccin, ce virus n'a pas été éradiqué et a encore causé plus de 140000 décès en 2018, un nombre en augmentation par rapport aux années précédentes [2]. Aucun traitement n'est disponible pour guérir l'infection par le virus de la rougeole. La maladie commence dans les voies respiratoires par l'infection des macrophages pulmonaires ou des cellules dendritiques exprimant le récepteur cellulaire de la molécule d'activation lymphocytaire Fl (signaling lymphocyte-activating molecule, SLAM/ CD150). En ce qui concerne les cellules dendritiques infectées, celles-ci migrent alors vers les ganglions lymphatiques et transmettent le virus aux lymphocytes $B$ et T activés exprimant SLAM, qui propagent l'infection par les systèmes vasculaires lymphatique et sanguin. Au stade avancé de l'infection, le virus de la rougeole infecte la surface baso-latérale des cellules épithéliales respiratoires par la protéine des jonctions d'adhérence nectine-4, ce qui permet l'excrétion du virus par voie aérienne et la propagation de l'épidémie [3]. À l'échelle moléculaire, les glycoprotéines d'attachement $\mathrm{H}$ et de fusion $\mathrm{F}$ forment la machinerie de fusion à la surface de la membrane virale. L'engagement du récepteur d'entrée par la protéine $\mathrm{H}$ déclenche la transition structurale de la protéine $F$ qui gouverne le processus de fusion des membranes virale et cellulaire, donc l'entrée de la ribonucléocapside virale dans le cytoplasme [4].

Le virus de la rougeole peut également se propager au système nerveux central et causer une encéphalite, presque toujours létale. La myéloencéphalite rougeoleuse à corps d'inclusions (MIBE) survient chez les patients immunodéprimés plusieurs semaines ou mois après l'infection, et la panencéphalite subaiguë sclérosante (PESS) se produit chez les patients immunocompétents encore plus tardivement, jusqu'à plusieurs décennies après l'exposition au virus survenant le plus souvent chez le très jeune enfant $[5,6]$. Les étapes précoces de la neuro-invasion restent particulièrement peu documentées faute d'outils disponibles, et la plupart des données proviennent d'analyses post mortem. Les infections pathologiques du système nerveux central conduisent généralement à une démyélinisation et sont associées à des lésions du cortex cérébral, de l'hippocampe, du thalamus, du tronc cérébral, et du cortex cérébelleux [6]. Les antigènes viraux sont généralement détectés dans les neurones et les oligodendrocytes, et beaucoup plus rarement dans les acteurs immunitaires majeurs du système nerveux central, les astrocytes et les cellules microgliales $[7,8]$. Le récepteur d'entrée du virus de la rougeole dans les cellules du système nerveux central est inconnu.

Des souris transgéniques exprimant artificiellement le récepteur humain du virus de la rougeole de façon ubiquitaire (souris SLAMtg) permettent de s'affranchir de toute variation liée à l'entrée du virus dans les cellules. En particulier, I'infection intranasale, par le virus de la rougeole, de souriceaux SLAMtg provoque une invasion virale du système nerveux central conduisant à un syndrome neurologique aigu létal, associé histologiquement à une astrogliose et 
A Tropisme du virus in vivo post-mortem déduit à partir de la présence d'antigènes viraux
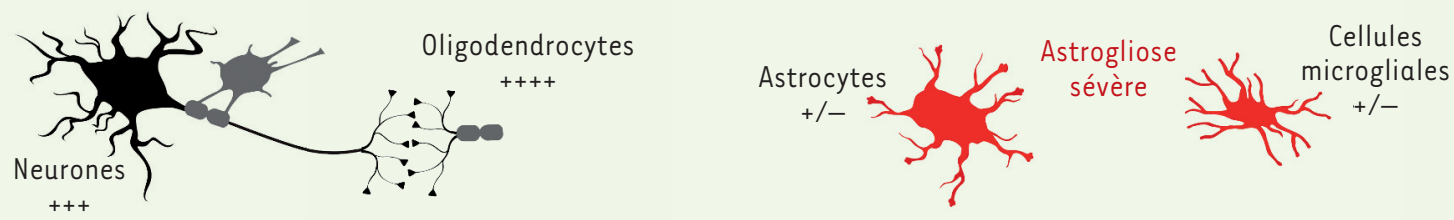

B

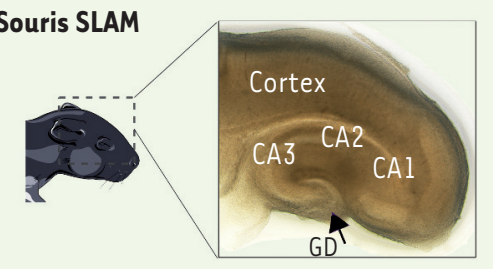

Culture organotypique d'hippocampe
Jour 0

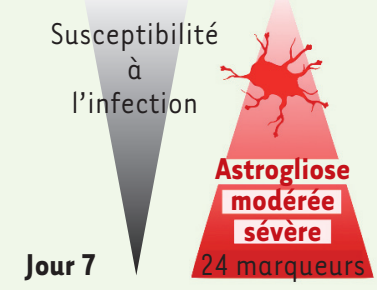

Jour 0

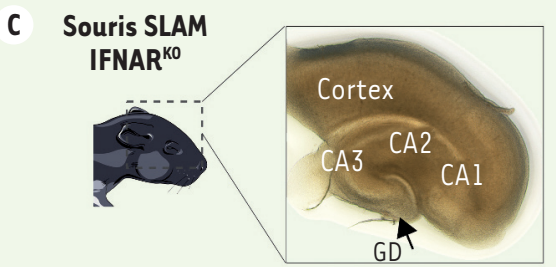

Culture organotypique d'hippocampe

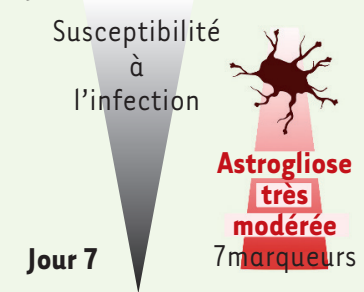

Neurones

Oligodendrocytes Astrocytes Cellules microgliales

Neurones

Oligodendrocytes

Figure 1. (A) Pathologie de l'infection par le virus de la rougeole dans le système nerveux central chez l'homme au moment du décès et chez la souris transgénique au moment de l'euthanasie. (B, C) Différence de développement d'une astrogliose dans les cultures organotypiques d'hippocampe, en l'absence de virus, de souris SLAMtg (B) et de souris SLAM IFNARKO (C), et impact sur la susceptibilité de ces cultures à l'infection par le virus de la rougeole. GD : gyrus denté, $\mathrm{CA}$ : corne d'Ammon.

un tropisme cellulaire du virus similaire à celui observé chez l'homme post mortem (Figure 1A). L'interféron de type I (IFN-I) joue un rôle important dans la lutte contre les infections virales [9]. Les souris SLAMtg ont été très utiles pour étudier le rôle clé de la signalisation par le récepteur de IFN-I (IFNAR) dans l'invasion du système nerveux central par le virus de la rougeole. Cette atteinte est en effet exacerbée chez des souris SLAMtg rendues génétiquement déficientes pour IFNAR (souris SLAM IFNAR ${ }^{K 0}$ ). Elle est alors létale même chez des animaux adultes, ce qui confirme le rôle crucial de la signalisation IFN-I dans le contrôle de l'infection in vivo [8].

Grâce aux souris SLAM IFNAR ${ }^{K 0}$, nous avons pu étudier si le tropisme du virus dépendait des mécanismes de l'immu- nité innée du cerveau [8]. Dans ce contexte, les cultures organotypiques cérébrales de rongeurs - des coupes standardisées de sous-structures cérébrales, issues de jeunes animaux et maintenues en culture pendant plusieurs jours voire semaines - offrent une opportunité unique d'étudier ex vivo les étapes précoces de l'infection dans des régions particulières du cerveau, non encore accessibles à l'expérimentation sous la forme d'organoïdes humains. De plus, ces cultures constituent le seul outil préservant les quatre types cellulaires du système nerveux central dans une organisation tridimensionnelle, avec des connexions physiologiques entre les cellules [10]. Nous avons observé une perte de susceptibilité à l'infection par le virus de la rougeole des cultures organotypiques d'hippocampe de souris SLAMtg et de souris SLAM IFNAR ${ }^{K O}$ après une semaine de culture. Cette perte de susceptibilité globale est corrélée à une induction inversement proportionnelle d'IFN- $\beta$ et des marqueurs de l'activation globale des systèmes tissulaires de défense et de réparation (S100B) et de l'activation spécifique des astrocytes (protéine acide fibrillaire gliale, GFAP). Ce résultat, associé au changement phénotypique des astrocytes, est indicateur de la mise en place d'une astrogliose. L'analyse du protéome associé aux cultures organotypiques d'hippocampe de souris SLAMtg après 7 jours de culture en l'absence d'infection a montré la surexpression de 84 des 111 protéines sécrétées testées, dont 18 des 24 marqueurs majeurs généralement 


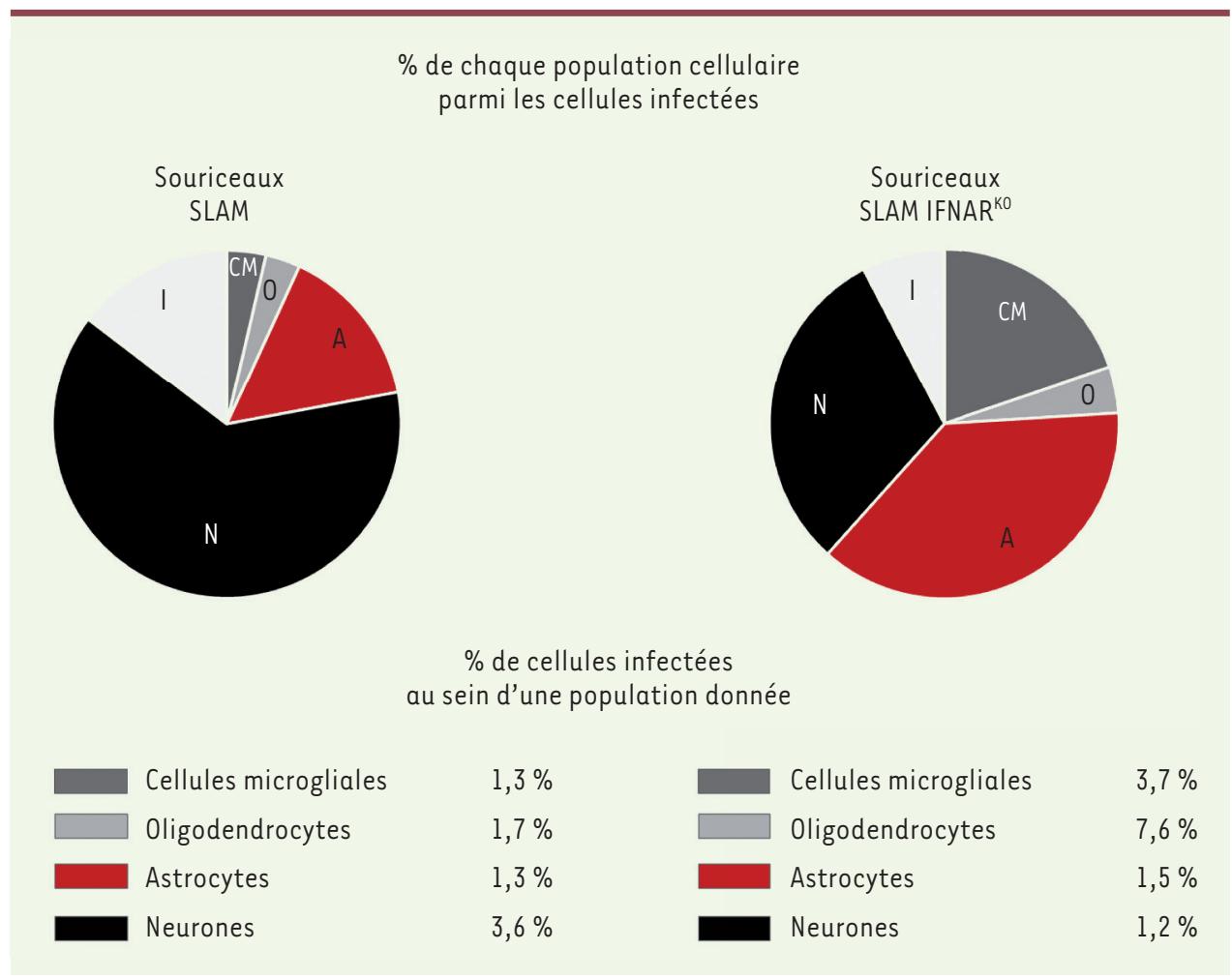

Figure 2. Permissivité des cellules neurales à l'infection par le virus de la rougeole dans des cultures organotypiques d'hippocampe de souris SLAMtg et de souris SLAM IFNAR ${ }^{K O}$. Les cultures organotypiques d'hippocampe ont été infectées avec $2 \times 10^{4}$ unités infectieuses (plaque-forming units, PFU) du virus de la rougeole (souche IC323) exprimant la protéine de fluorescence verte VR-IC323eGFP. Les cellules isolées, obtenues après digestion enzymatique par la papaïne, suivie d'une dissociation mécanique des cultures 24 heures après l'infection, ont été marquées avec des anticorps spécifiques pour effectuer une analyse par cytométrie en flux. La distribution cellulaire de l'infection (diagrammes circulaires) repré-

sente le pourcentage de chaque population cellulaire parmi l'ensemble des cellules infectées : neurones ( $N$ ), astrocytes (A), oligodendrocytes $(0)$, cellules microgliales (CM), et cellules de nature indéterminée (I). Le pourcentage de cellules infectées au sein de chacune des quatre populations cellulaires (neurones, astrocytes, oligodendrocytes, et cellules microgliales) est également indiqué pour évaluer comparativement la contribution de chaque population à l'infection dans les deux modèles organotypiques murins.

observés dans le développement de l'astrogliose modérée à sévère (Figure 1B). En l'absence d'IFNAR, seules 27 protéines sécrétées étaient surexprimées (après 7 jours de culture en l'absence d'infection), dont seulement 7 associées à l'astrogliose, et aucune n'était associée à une activité antivirale connue (Figure 1C). En revanche, l'infection des cultures organotypiques d'hippocampe de souris SLAMtg par le virus de la rougeole a conduit à la surexpression significative de 50 protéines sécrétées, dont 44 comptent parmi les protéines induites naturellement dans les cultures. Ainsi, l'infection par ce virus a exacerbé la part de réponse de l'astrogliose sous la dépendance de I'IFN-I.

L'analyse en microscopie à fluorescence, après 24 heures, des cultures organotypiques d'hippocampe de souris SLAMtg ou SLAM IFNAR ${ }^{K O}$ infectées le jour de leur préparation a montré la permissivité des neurones, oligodendrocytes, astrocytes, et cellules microgliales à l'infection. La distribution de l'infection dans les cellules des cultures issues de souris SLAMtg, suivie par cytométrie en flux après digestion enzymatique des coupes tissulaires par la papaïne, dissociation des cellules et immunomarquages, montre que les neurones constituent plus de $60 \%$ des cellules infectées, loin devant les astrocytes infectés (15\%), et les quelques pourcents d'oligodendrocytes et de cellules microgliales infectés, tandis que dans les cultures issues de souris SLAM IFNAR ${ }^{K O}$, dépourvues de IFNAR, on observe une homogénéisation de la distribution des cellules infectées, avec presque autant de neurones que d'astrocytes infectés (30\% et $38 \%$ respectivement), environ $20 \%$ de cellules microgliales infectées, environ $5 \%$ d'oligodendrocytes infectés, et autant de cellules «indéter- minées » (comportant simultanément le marqueur oligodendrocytaire et un des autres marqueurs) (Figure 2). En tenant compte des proportions des différents types cellulaires dans la culture organotypique, nous avons confirmé que, dans le modèle de souris SLAMtg, les neurones constituent la population contribuant majoritairement à l'infection. En revanche, en l'absence de IFNAR, les astrocytes sont aussi permissifs à l'infection que les neurones, les oligodendrocytes et cellules microgliales devenant alors des contributeurs majeurs de l'infection. Enfin, si l'infection par le virus de la rougeole est effectuée 7 jours après la mise en culture organotypique, aucune cellule astrocytaire ou microgliale des cultures issues de souris SLAMtg n'est infectée, contrairement à ce qui est observé dans les cultures issues des souris SLAM IFNAR $^{\text {KO }}$ (Figure IB, C). 
Cette étude met en évidence plusieurs caractéristiques des réponses inflammatoires liées aux interférons de type I, et de l'astrogliose des explants cérébraux, faisant suite à l'infection par le virus de la rougeole. Elle révèle la différence de susceptibilité des cellules à l'infection, notamment la résistance des astrocytes et des cellules microgliales via la signalisation IFNAR, même lorsque l'entrée du virus dans les cellules cérébrales murines est artificiellement rendue possible par l'expression ectopique du récepteur SLAM humain. Sans que l'on puisse exclure la possibilité d'une différence de mécanisme d'entrée entre les différentes populations cellulaires cérébrales, ces observations expliquent au moins partiellement l'inconstance des données post mortem concernant la présence d'antigènes du virus de la rougeole dans les astrocytes et des cellules microgliales chez l'homme. Par ailleurs, si l'infection dans nos deux modèles animaux, souris SLAMtg et souris SLAM IFNAR ${ }^{K O}$, se termine par un syndrome neurologique mortel dans les deux cas, les premiers évènements conduisant à une encéphalite sont différents en termes de sensibilité cellulaire et de molécules sécrétées dans le parenchyme du système nerveux central. II reste à déterminer si cette plus faible susceptibilité des astrocytes et des cellules microgliales à l'infection par le virus de la rougeole et leur capacité à contrôler l'infection par la voie IFN jouent un rôle dans la sélection ou l'acquisition des mutations caractéristiques observées dans les séquences virales isolées de patients décédés d'une encéphalite rougeoleuse. II faudra pour cela étudier en détail l'évolution virale à long terme au cours d'une propagation de l'infection du système nerveux central. $\diamond$

Type I interferon and selective permissiveness of central nervous system to measles virus infection

\section{LIENS D'INTÉRÊT}

Les auteurs déclarent n'avoir aucun lien d'intérêt concernant les données publiées dans cet article.

\section{RÉFÉRENCES}

1. Holzmann $H$, Hengel $H$, Tenbusch M, et al. Eradication of measles: remaining challenges. Med Microbiol Immunol 2016 ; 205 : 201-8.

2. Organisation mondiale de la santé. Plus de 140000 personnes meurent de la rougeole tandis que le nombre de cas augmente dans le monde entier. 2019 Joint News Release.

3. Laksono BM, Vries RD de, McQuaid S, et al. Measles virus host invasion and pathogenesis. Viruses 2016; $8: 210$.

4. Jurgens EM, Mathieu C, Palermo LM, et al. Measles fusion machinery is dysregulated in neuropathogenic variants. MBio $2015 ; 6$ : 1-12.

5. Griffin DE. Measles virus and the nervous system. In : Tselis AC, John B, eds. Handbook of clinical neurology. New York :Elsevier, 2014 : 577-90.

6. Ferren M, Horvat B, Mathieu C. Measles encephalitis: towards new therapeutics. Viruses 2019; $11: 1017$.

7. Duprex WP, McQuaid S, Hangartner L, et al. Observation of measles virus cell-to-cell spread in astrocytoma cells by using a green fluorescent protein-expressing recombinant virus. J Virol 1999 ; $73: 9568-75$

8. Welsch JC, Charvet B, Dussurgey S, et al. Type I interferon receptor signaling drives selective permissiveness of astrocytes and microglia to measles virus during brain infection. J Virol 2019 ; 93.

9. Gerlier D, Lyles DS. Interplay between innate immunity and negative-strand RNA viruses: towards a rational model. Microbiol Mol Biol Rev 2011 ; 75 : 468-90.

10. Welsch J, Lionnet C, Terzian C, et al. Organotypic brain cultures: a framework for studying CNS infection by neurotropic viruses and screening antiviral drugs. Bioprotocol $2017 ; 7$.

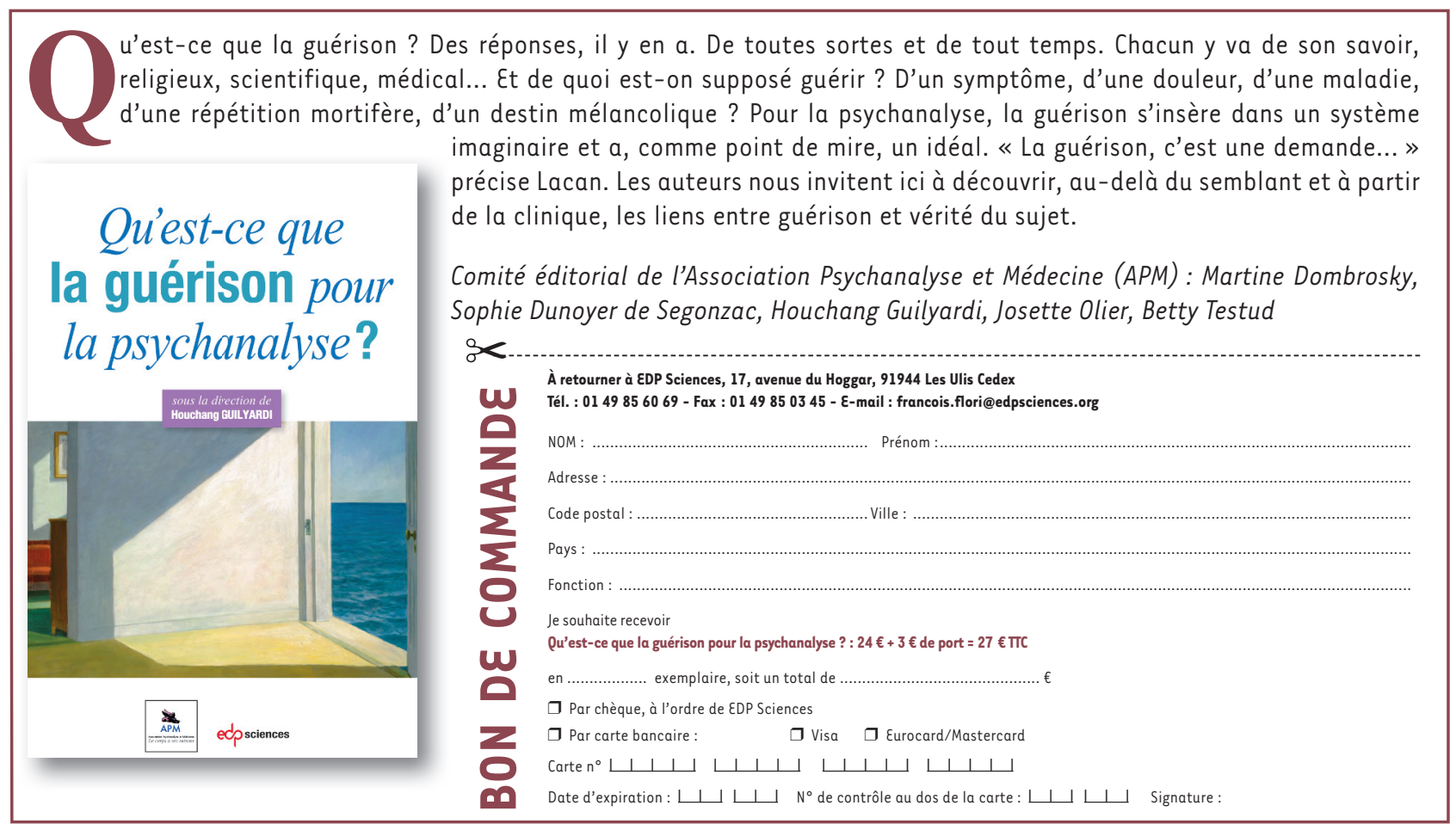

